\title{
PTA DEPOSITION OF W+Cu COMPOSITES FOR FUSION REACTORS
}

\author{
${ }^{1}$ Jiří MATĚJIĆEEK, ${ }^{2} J a n$ VOSÁHLO, ${ }^{2}$ Pavel ROHAN \\ ${ }^{1}$ Institute of Plasma Physics of the Czech Academy of Sciences, Prague, Czech Republic, EU, \\ matejicek@ipp.cas.cz \\ ${ }^{2}$ Faculty of Mechanical Engineering, Czech Technical University in Prague, Czech Republic, EU, \\ h.vosahlo@seznam.cz, Pavel.Rohan@fs.cvut.cz
}

\section{https://doi.org/10.37904/metal.2021.4249}

\begin{abstract}
Tungsten-based materials are the most prospective candidates for plasma-facing components of future fusion devices, such as ITER and DEMO. For joining of the tungsten armor to the cooling or structural parts, composites and graded layers can be used as stress-relieving interlayers.

This work presents a feasibility study of $\mathrm{W}_{+} \mathrm{Cu}$ composites preparation by plasma transferred arc (PTA) cladding on tungsten substrates. Basic optimization of the process was carried out to achieve dense and well bonded layers. Formation of a functionally graded material (FGM) was also attempted. The structure, compositional profiles and fracture surfaces of the claddings prepared at different conditions were characterized.
\end{abstract}

Keywords: Tungsten-copper composites, plasma transferred arc cladding, fusion materials

\section{INTRODUCTION}

Thermonuclear fusion is a promising source of energy supply for the future, with a number of potential advantages, such as stability, safety, abundance of fuel, absence of fossil fuels and therefore minimal greenhouse gas production, high efficiency of the energy production, minimal dependence on locality [1]. Its successful realization depends strongly on materials able to function in the harsh environment - in the European Fusion Roadmap, four out of seven main challenges are connected with materials [2]. This particularly concerns materials for the so-called plasma facing components, which will be subjected to a combination of various loading - high heat and particle fluxes from the plasma, physico-chemical and mechanical loads [3]. For the plasma facing surface, tungsten is the main candidate material, thanks to its favorable properties, such as high melting point, good thermal conductivity, high-temperature strength, high resistance to erosion by plasma species, etc. [4,5]. The plasma facing armor needs to be joined to a cooling system, foreseen to be made from a copper alloy or low activation stainless steel. This presents a particular challenge, as the joint of two dissimilar materials develops high stresses upon temperature excursions, primarily due to difference in thermal expansion [6]. The stress concentration at the interface can be alleviated by joining layers with intermediate properties [7]. These could be either from a third material (the selection of these is however rather limited) or composites consisting of the armor and cooling system materials [8]. Moreover, W-rich composites (so-called "tungsten heavy alloys") are also considered for the plasma facing armor, primarily thanks to their higher ductility and easier fabrication compared to tungsten $[9,10]$.

The composites can be produced by a variety of techniques. These include powder metallurgy techniques, such as hot pressing [11], spark plasma sintering [12], microwave sintering [13], melt infiltration into W skeleton [14], combustion synthesis and centrifugal infiltration [15], as well as coating/cladding techniques, such as cold spraying [16], plasma spraying [17,18,19], high-velocity oxy-fuel spraying [20] or plasma transferred arc cladding [21]. The latter group of techniques has a major advantage in the possibility to reduce or eliminate 
the need for joining. Other potential advantages include the ability to coat large areas, high material throughput and the possibility of compositional control, enabling the formation of functionally graded materials (FGMs) that replace sharp interfaces with a gradually varying composition [22].

The PTA cladding (also called PTA hardfacing or overlay welding) consists of powder material being introduced into a plasma jet, formed in gaseous medium (typically argon) by an electric arc, where it is heated and propelled towards the base material. The transferred arc attaches to the base material and contributes to melting both the base material and the filler material [23,24]. The resulting melt pool ensures strong metallurgical bonding and facilitates the formation of dense layers. A large variety of metallic materials, as well as composites, can be processed by this technique. Recently, pilot experiments with $\mathrm{W}+\mathrm{Ni}$ and $\mathrm{W}+\mathrm{Cu}$ claddings on steel substrates were carried out [21]. Due to base material melting and dilution, steel species penetrated throughout the cladding and reacted with tungsten, forming brittle intermetallics. On the other hand, initial experiments on copper substrates revealed difficulty in forming dense layers, which was ascribed to rapid heat removal from the surface through the highly conductive copper base material [25]. Therefore, the current experiments were carried out using $\mathrm{W}$ and $\mathrm{Cu}$ powder mixture on $\mathrm{W}$ substrates. The aims of this work were to assess the feasibility of forming composite cladding for this combination of materials, perform initial optimization of the process towards dense layers and provide basic characterization of the claddings.

\section{EXPERIMENTAL DETAILS}

As the base material, $5 \mathrm{~mm}$ thick tungsten plates prepared by powder metallurgy (Porexi, Ostrava, Czech Republic) were used. As the filler materials, pure tungsten (mean size around $80 \mu \mathrm{m}$; GTP, Towanda, USA) and pure copper (mean size around $170 \mu \mathrm{m}$; Stamont, Žilina, Slovakia) powders were used. The tungsten powder had angular, nearly equiaxial shape; the copper powder had mostly round, but highly irregular shapes as a result of melt atomization [21]. Prior to cladding, the powders were dried in an oven for several hours. The powders were fed into the plasma jet at various ratios, in an attempt to form graded layers. To facilitate setting relative feed rates of the powders for desired weight or volumetric ratios, their apparent densities were determined. These were $8.63 \mathrm{~g} / \mathrm{cm}^{3}$ for tungsten and $3.48 \mathrm{~g} / \mathrm{cm}^{3}$ for copper.

For the cladding, a PPC 250 R6 automatic plasma surfacing machine (KSK, Česká Třebová, Czech Republic) was used. The cladding was performed in an in-house built protective chamber being flushed with inert gas, to prevent oxidation. During the experiments, the following process parameters were varied: torch current, plasma forming gas and powder mixing ratios. All other parameters were kept constant and are described in detail in [26]. Prior to cladding, the base material was preheated by the torch without powder feeding. Each cladding was made from five layers with the following weight ratios of the fed powders: $15 \%, 30 \%, 50 \%, 75 \%$ and $100 \% \mathrm{Cu}$.

For an overview of the cladding structure, light microscopy (Neophot 32, Carl Zeiss, Göttingen, Germany) was used on metallographic sections. For detailed microstructural observations, scanning electron microscopy (SEM) was used (EVO MA15, Carl Zeiss SMT, Oberkochen, Germany). Energy-dispersive spectroscopy (EDS; XFlash5010, Bruker, Berlin, Germany) integrated in the SEM was used to quantify the composition. Fracture surfaces of selected samples were also observed by SEM.

\section{RESULTS}

The work consisted of five cladding experiments, between which one or more process parameters were modified. The parameters for the first experiment were set based on previous experience with cladding Wbased materials [25,27]. Visual inspection of the first layer indicated insufficient melting, therefore, the torch current was gradually increased for the subsequent layers. Overview of the cross section is shown in Figure 1a, detailed microstructures are shown in Figure 1b-d. From the figure, one can conclude that base material melting likely did not occur, as it maintains a uniform thickness and straight interface. Nevertheless, 
good bonding of the cladding without any flaws can be seen (Figure 1b). In the middle of the cladding, larger tungsten regions are observed. These could have originated either from imperfect mixing of the two powders or from tungsten powder being caught in the nozzle and being released in larger clusters. These regions are fully dense, indicating the tungsten particles were molten and fused together. A large copper-only region is visible on the top left side of the cladding; likely a result of the copper floating on the surface of the melt pool during the cladding process due to its lower density. The tungsten particles in the bottom and middle regions of the cladding have markedly modified shapes, indicating that they were molten fully or at least to a significant degree. In the top layer, their shape is nearly equiaxial, indicating only moderate degree of melting. The interfaces between tungsten and copper were sharp and without any voids or cracks. Therefore, no interdiffusion or metallurgical reaction has taken place (as was expected from mutual insolubility of these materials), while a good bonding in the liquid phase has occurred. The images also show a large degree of layer intermixing, without visible distinction of the individual passes or an overall compositional gradation.
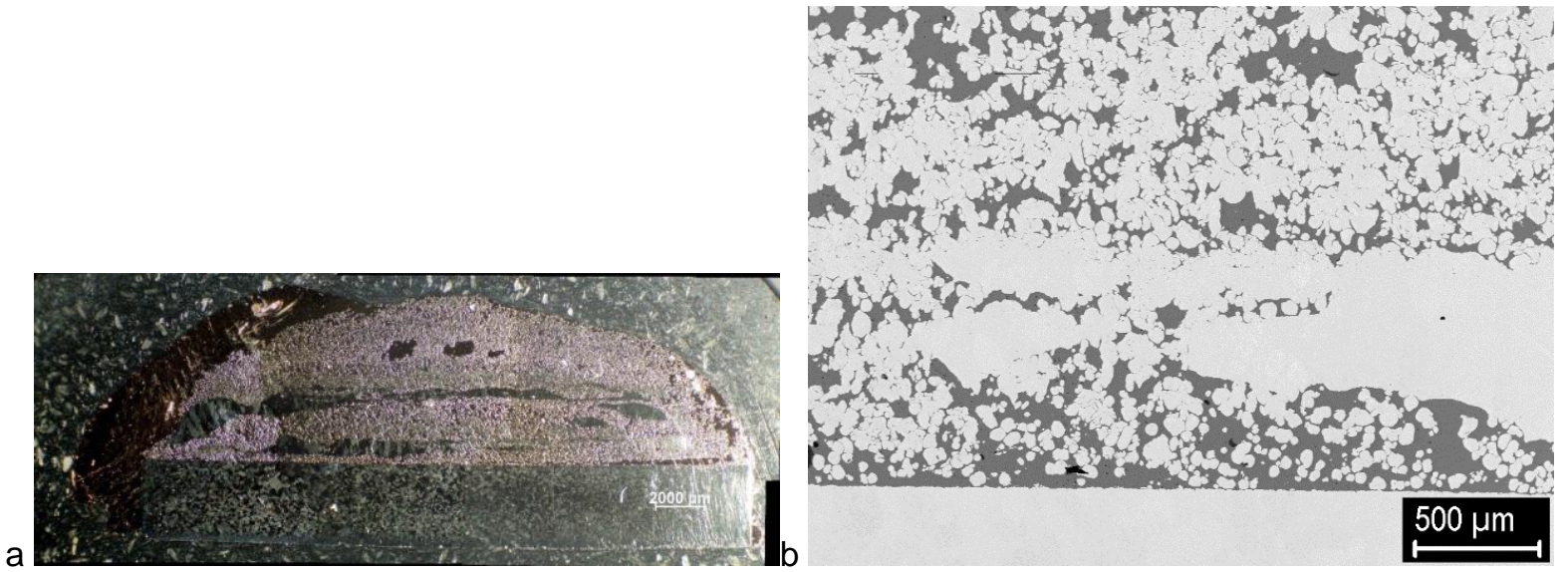

a
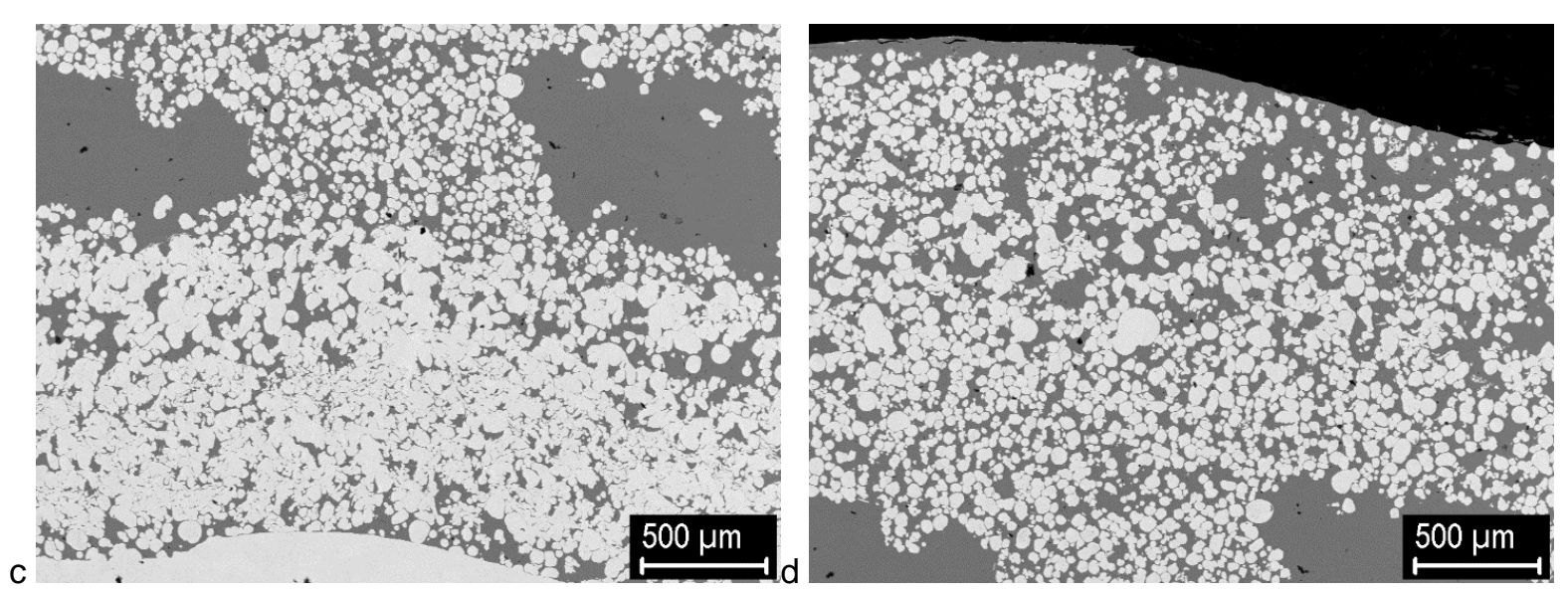

Figure 1 Cross sections of cladding no. 1: a) overview (light microscopy), b-d) detailed microstructures near the interface, in the middle and near the surface, respectively (SEM, backscattered mode)

For the second experiment, the parameters were changed with the aim of more intense melting of the filler material. Therefore, torch current was moderately increased already from the first pass. At the same time, the lateral motion ("swing") velocity of the torch was reduced, to provide more intense heating of the base material, while the powder feed rates were reduced and torch traverse velocity was increased, to prevent filler material accumulation at the edges of the cladding. Cross sections of the cladding are shown in Figure 2. Similarly to the first experiment, there appears to be little or no melting of the base material, still with a good bonding with the cladding. Again, larger W-only clusters are seen within the cladding, but no large Cu regions on the surface. The individual W particles have mostly equiaxial shape, indicating a lower degree of melting. Occasional small 
pores were observed. The layers were again heavily intermixed, resulting in no global change of composition from the base towards the surface. This is also indicated by the EDS line profiles shown in Figure 3.
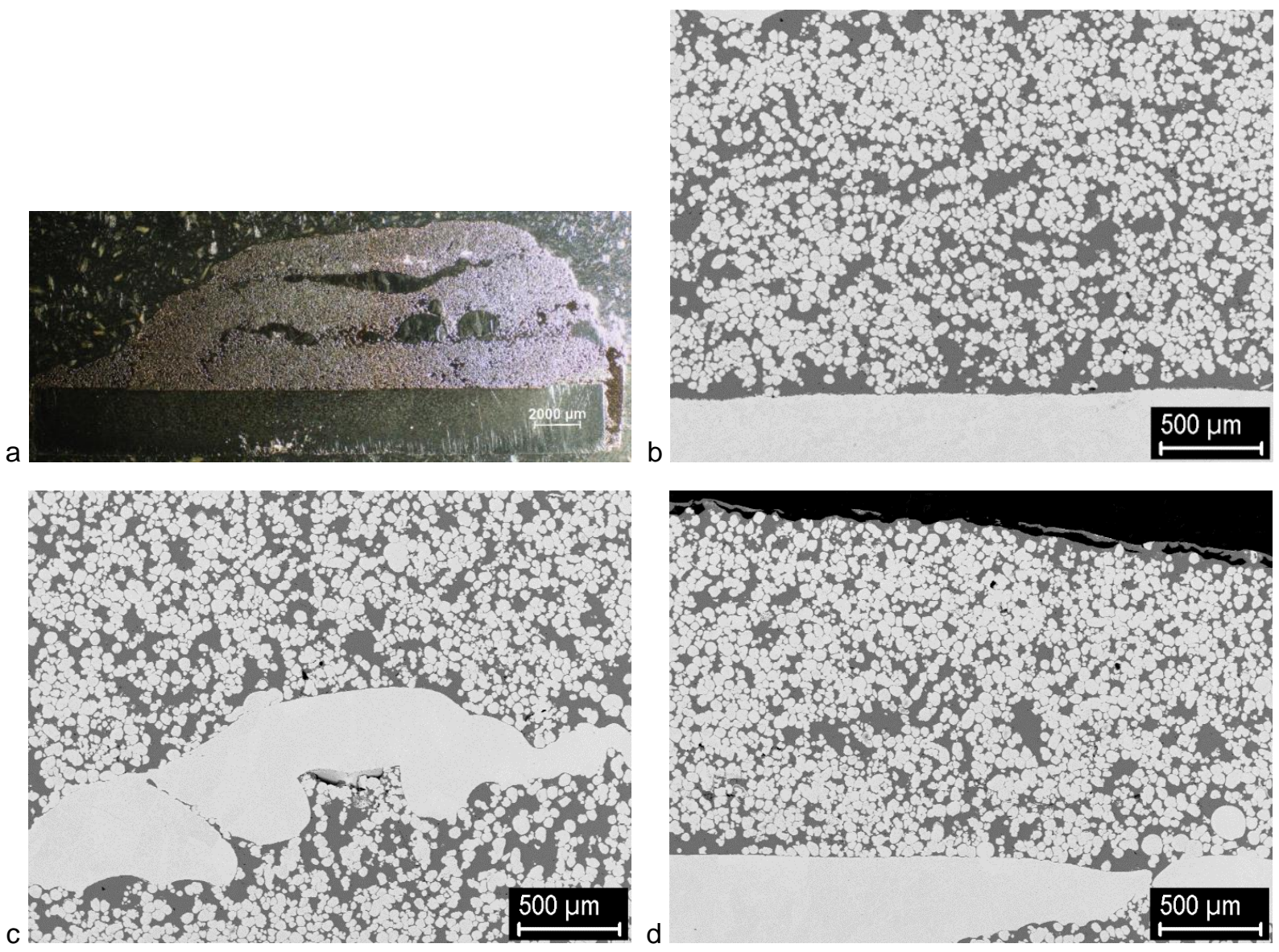

Figure 2 Cross sections of cladding no. 2: a) overview, b-d) detailed microstructures near the interface, in the middle and near the surface, respectively
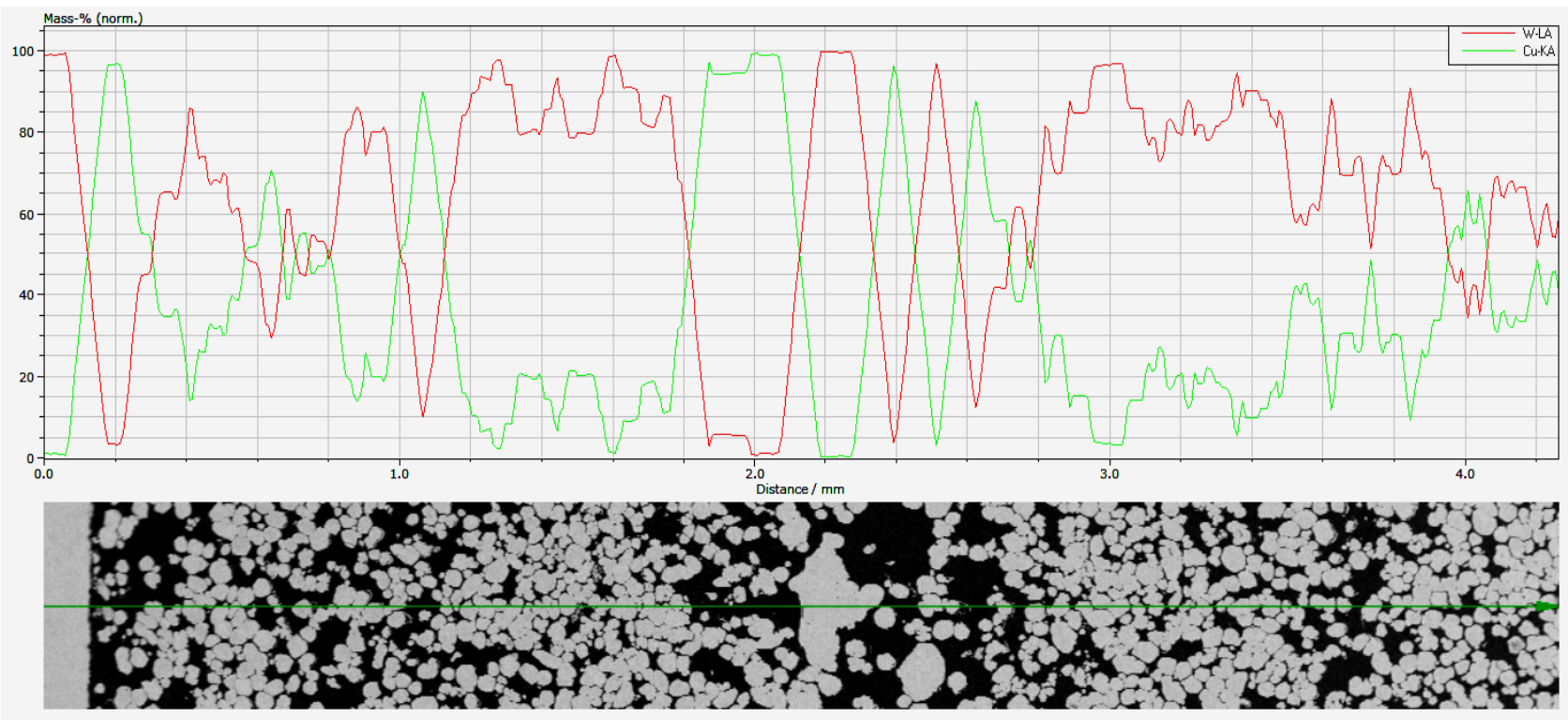

Figure 3/1 Compositional profile (EDS line scan) along the thickness of cladding no. 2 (top image: first $\sim 4$ $\mathrm{mm}$, bottom image: last $2 \mathrm{~mm} ; \mathrm{W}$ - red line, $\mathrm{Cu}$ - green line) 


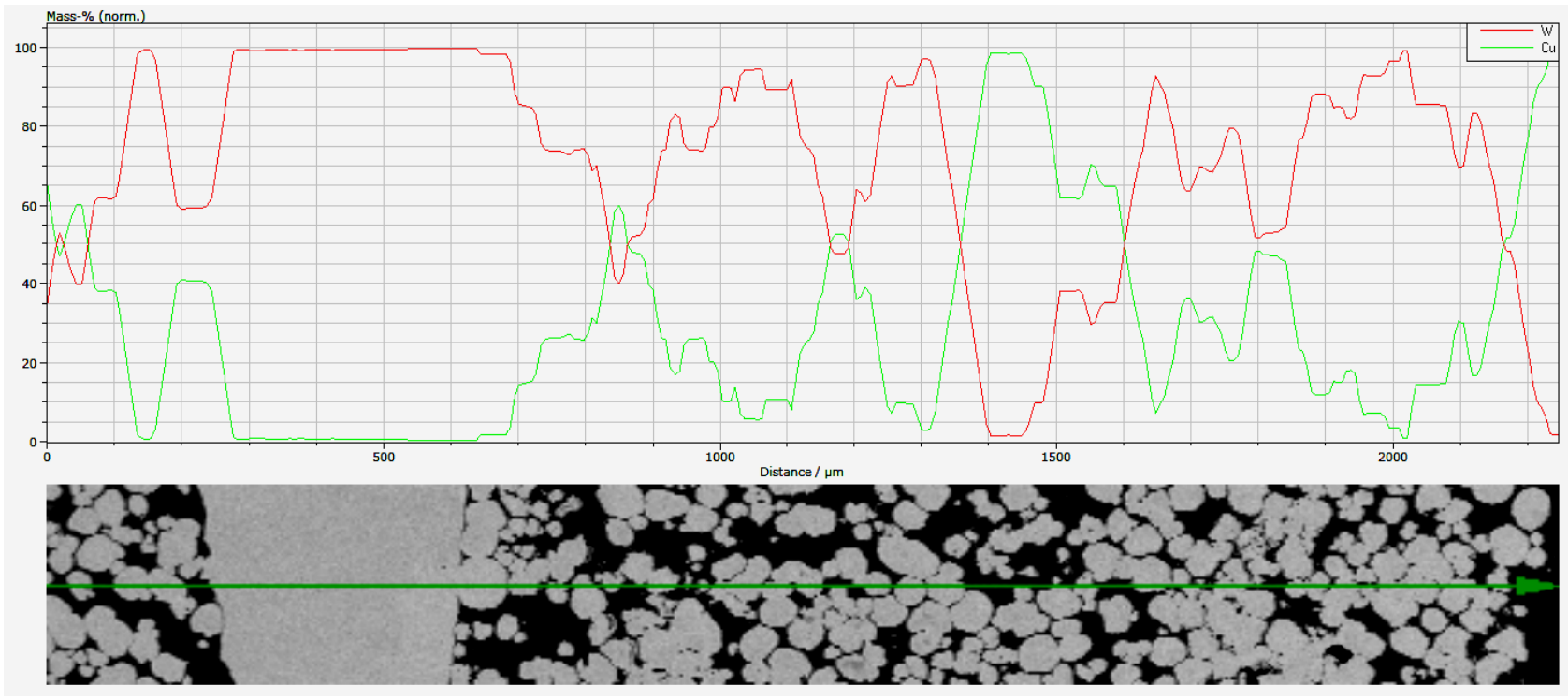

Figure 3/2 Compositional profile (EDS line scan) along the thickness of cladding no. 2 (top image: first $\sim 4$ $\mathrm{mm}$, bottom image: last $2 \mathrm{~mm} ; \mathrm{W}$ - red line, $\mathrm{Cu}$ - green line)
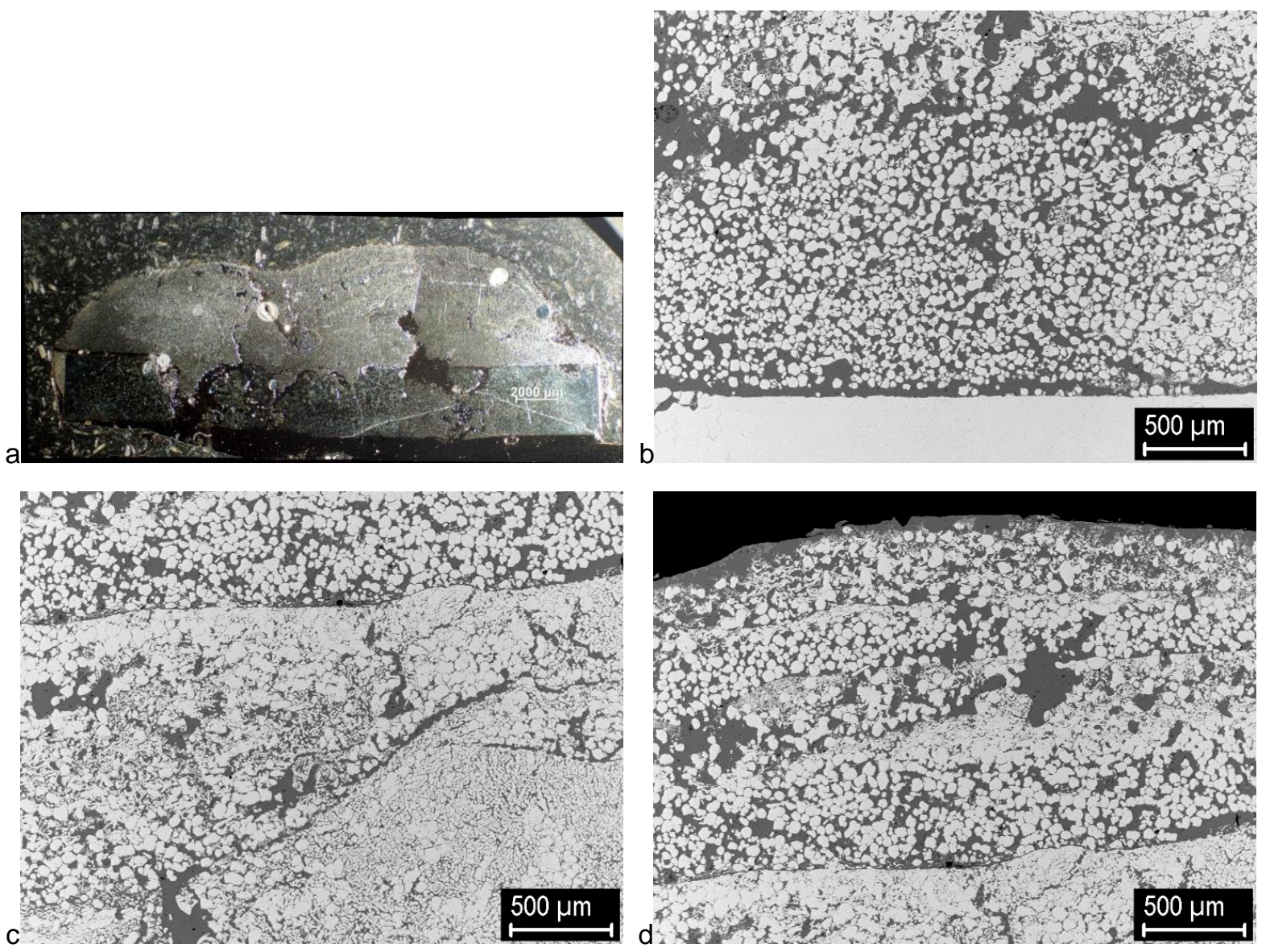

Figure 4 Cross sections of cladding no. 3: a) overview, b-d) detailed microstructures near the interface, in the middle and near the surface, respectively

The third experiment was aimed at further increase of the filler material melting. For this purpose, separate test cladding of single layers with various process gases was performed. From these, the highest temperatures 
were achieved for the combination of $\mathrm{Ar}+5$ vol\% $\mathrm{H}_{2}$ as the plasma gas and $\mathrm{Ar}+\mathrm{He}$ as the carrier and sheath gas. Furthermore, copper baseplate, on which the tungsten plates were placed, was replaced by a steel baseplate, to reduce the heat removal from the base material to the baseplate. For increased melting of the filler materials, the deposited layers (except the last two, which were rich in copper) were remelted by a torch pass without powder feeding. Cross sections are shown in Figure 4. This parameter combination led to significant heat input to the base material, which however, resulted in cracking of the tungsten plate and mutual mixing of the copper and steel in the molten state. A consequence of this was the formation of intermetallic phases on the interface with tungsten grains in the bottom layer (Figure 5). This took place only in small region, due to the reaction with the steel baseplate, while majority of the cladding consisted of copper and tungsten only, with no third phases. Overall, a rather uniform mixing of copper and tungsten was observed, without "islands" of pure W or pure Cu observed in the previous runs. Due to the remelting passes, distinct layering can be observed, with finer tungsten grains towards the top of each pass. To qualitatively assess the effect of tungsten grain size on the mutual bonding with copper, small samples cut out from the cladding were broken and the fracture surfaces observed in SEM. An example of the fracture surface is shown in Figure 6a. The image shows that prevalent failure mode was either an intragranular fracture of the tungsten grains (center, top right, bottom right grains) or a debonding of the thin intermetallic layer from the tungsten grains (top left, top right, bottom left and bottom right regions). There was no significant separation of the copper matrix and the tungsten grains, while signs of ductile deformation in the matrix are clearly seen (e.g. around the central $\mathrm{W}$ grain in the figure). Thus, the copper matrix retained good bonding with the tungsten grains, regardless of the modified morphology. Figure $6 \mathbf{b}$ shows a fracture in the refined microstructure region, where intense mixing of the two phases took place. The tungsten grains have more complex shape, but the facture has similar character, i.e. intragranular fracture in tungsten and ductile deformation in copper.
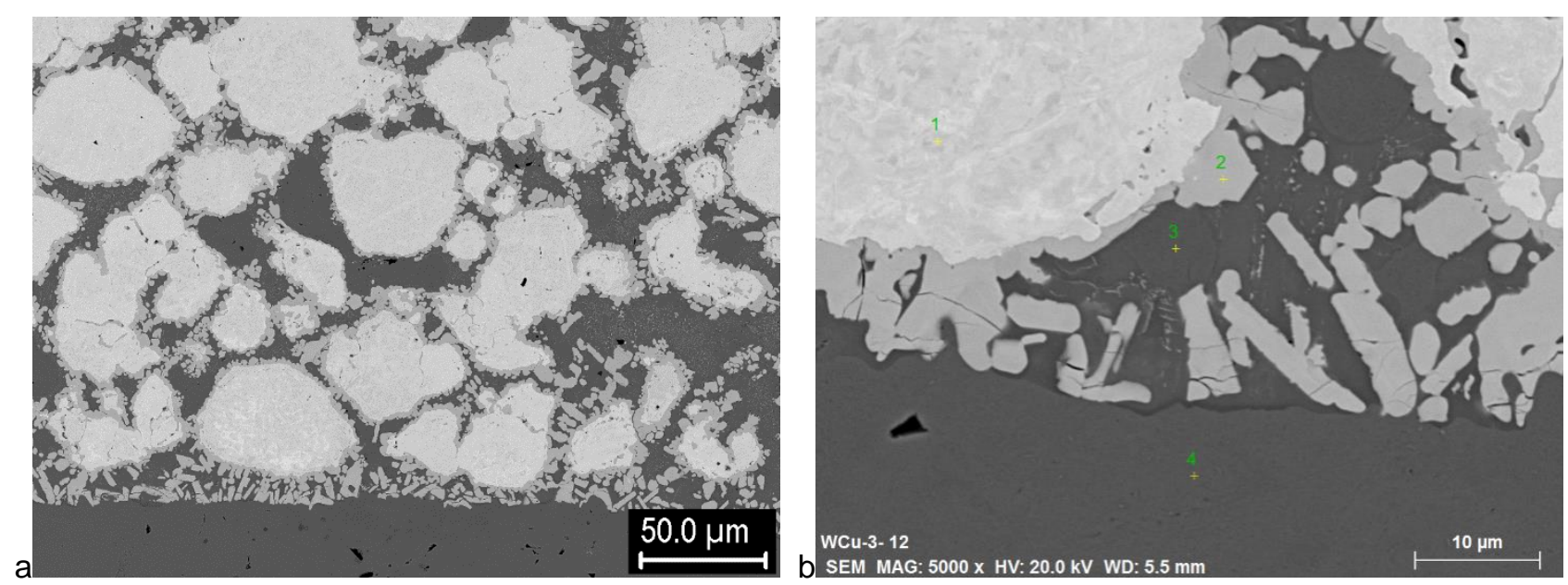

Figure 5 Microstructure of the steel-affected bottom layer of cladding no. 3, showing the intermetallic formation (a), enlarged view showing points of local EDS analysis, whose results are summarized in Table 1.

Table 1 Local elemental composition (wt\%) determined by EDS in cladding no. 3 in points marked in Figure 5b).

\begin{tabular}{|c|c|c|c|c|c|}
\hline point & $\mathbf{0}$ & $\mathbf{C r}$ & Fe & Cu & W \\
\hline 1 & 1.1 & - & - & - & 98.9 \\
\hline 2 & 0.9 & 6.7 & 28 & - & 64.4 \\
\hline 3 & 0.7 & - & 4.5 & 94.6 & 0.1 \\
\hline 4 & - & 0.6 & 3.5 & 95.6 & 0.3 \\
\hline
\end{tabular}



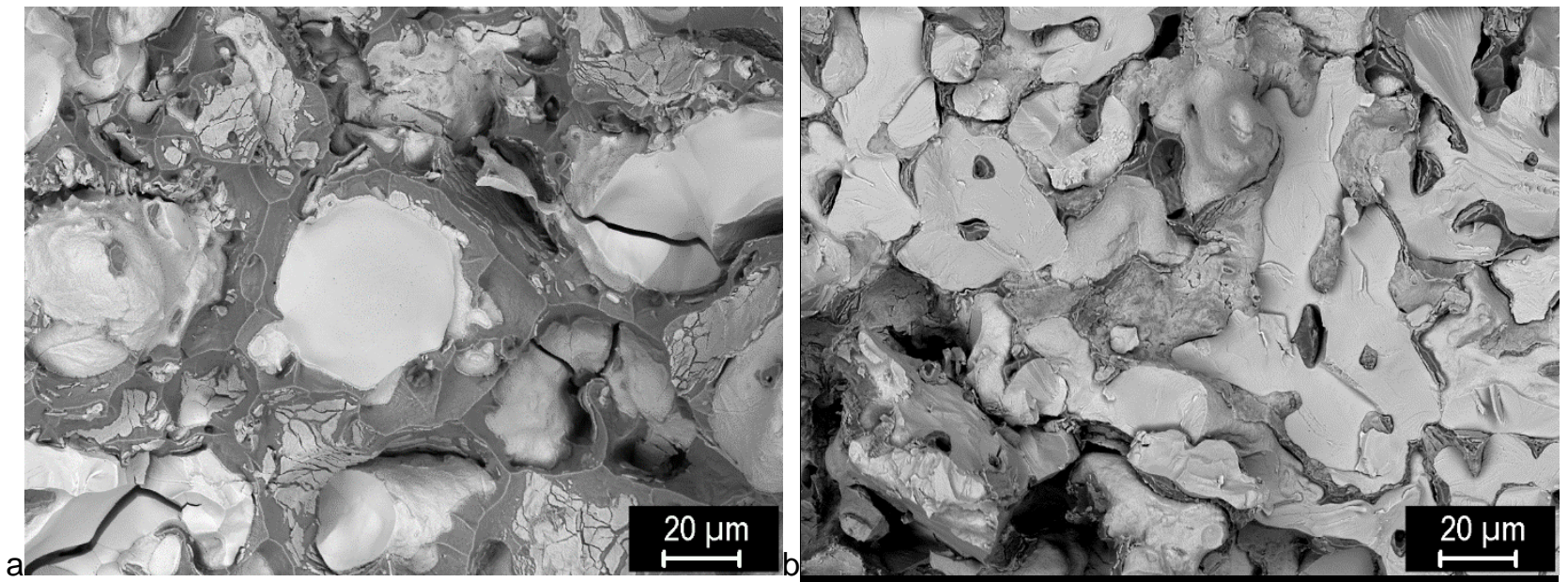

Figure 6 Fracture surface of cladding no. 3 (SEM, backscattered electron mode):a) region with nearly equiaxial $\mathrm{W}$ grains, $b$ ) region of intense mixing with complex $\mathrm{W}$ grains
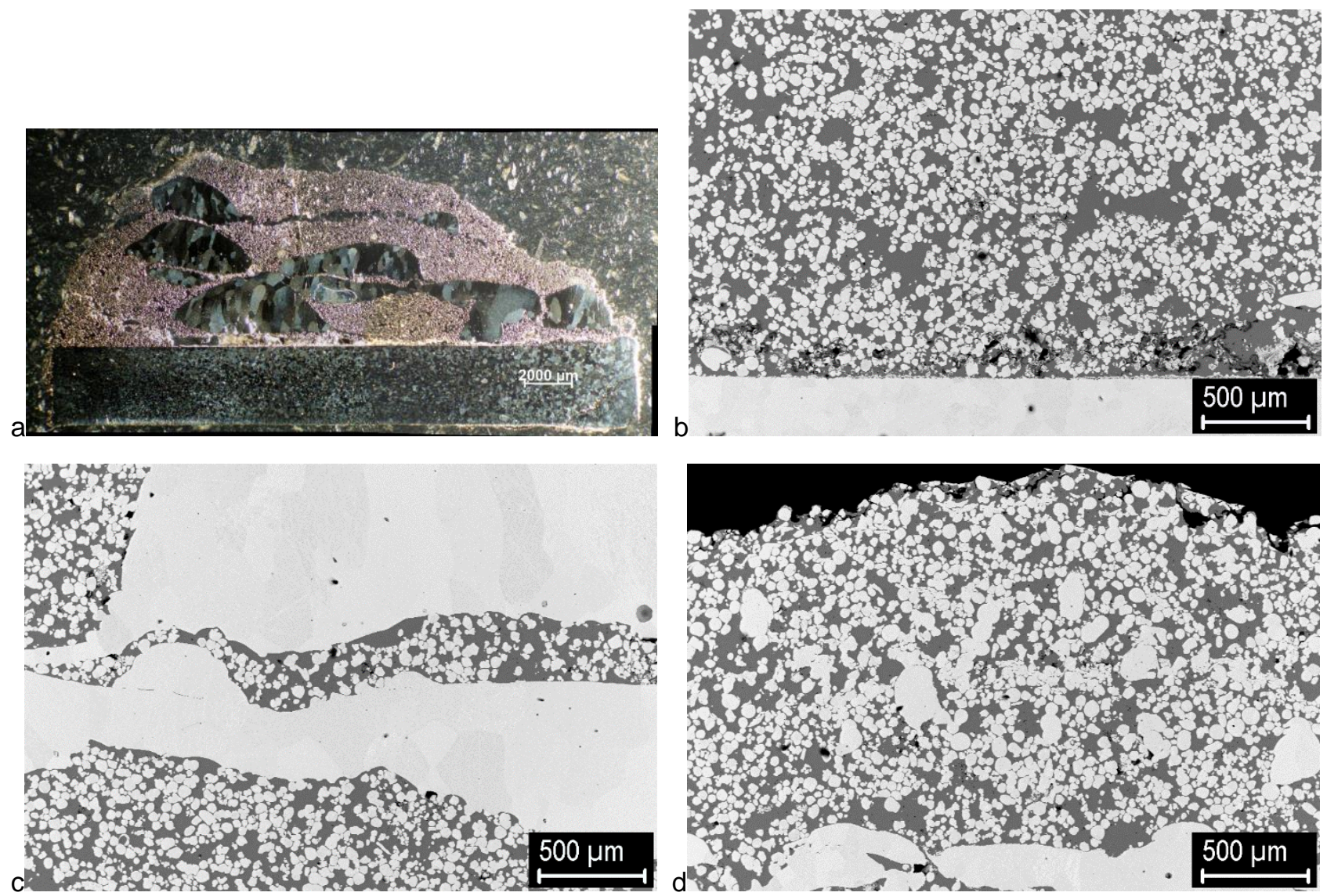

Figure 7 Cross sections of cladding no. 4: a) overview, b-d) detailed microstructures near the interface, in the middle and near the surface, respectively

Next experiment was carried out with the same process gas combination, but with further increased torch current. Graphite sheet was added between the baseplate and tungsten plate, to prevent their interaction. No intermediate layer remelting was performed. The cross sections are shown in Figure 7. This time, the base material apparently remained intact, however, due to irregular powder feeding, there are large tungsten islands and the cladding has overall irregular shape. Apart from this, the microstructure is very similar to those from 
experiments no. 1 and 2. Some porosity was observed at the interface; this likely originates from the powder feeding problems, because of which the first layer had to be repeated.

Since the graphite sheet provided additional thermal insulation, for the fifth experiment the heat input to the part was moderately reduced by lowering the torch current. The irregular powder feeding in this experiment led to fusing of the part with the steel baseplate on the sides and local interaction with tungsten, leading again to local intermetallics formation. The powder feeding issue can also account for the occasional presence of larger pores and copper islands in the cladding, although previously observed tungsten islands were not seen this time (Figure 8).
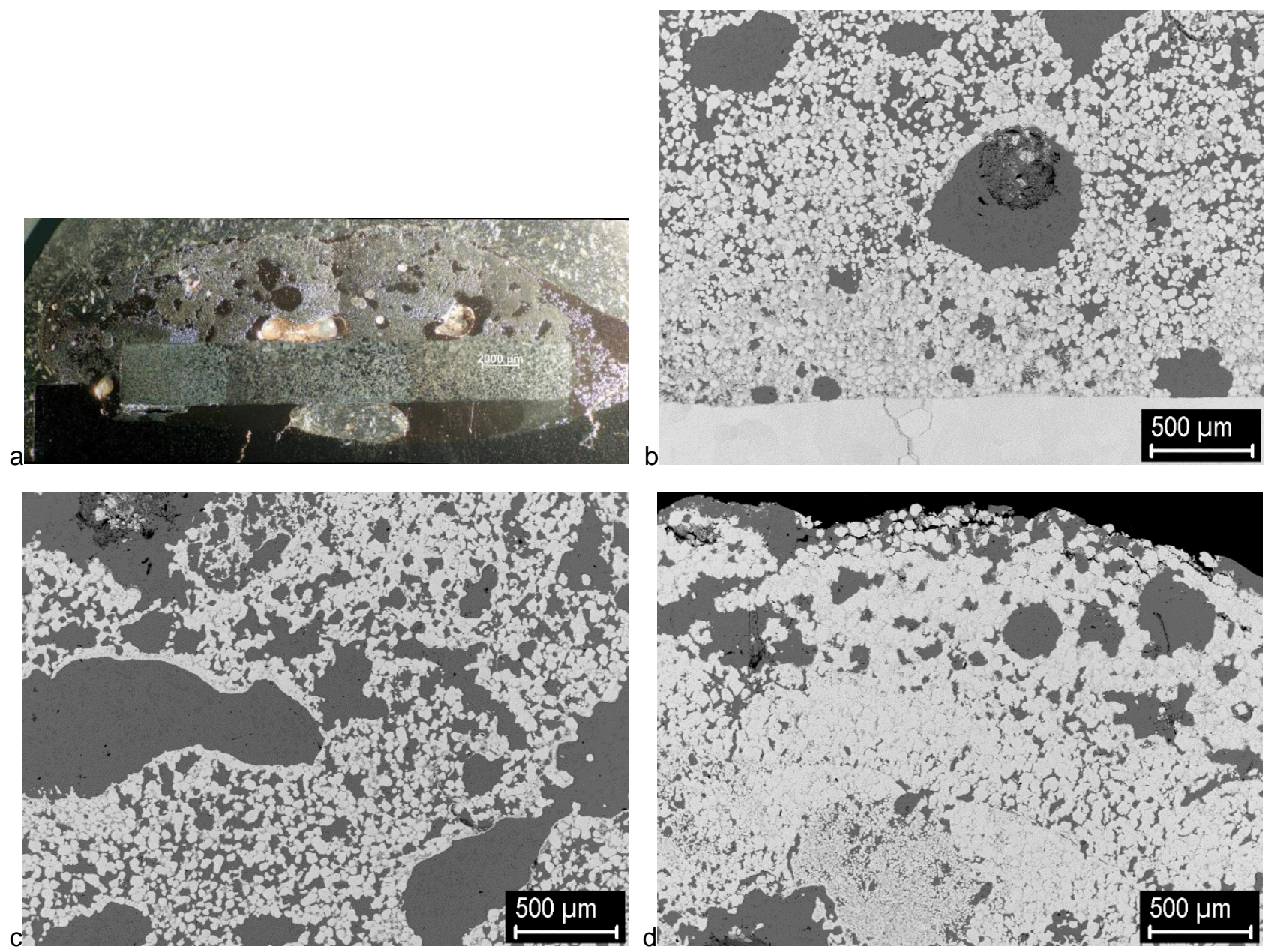

Figure 8 Cross sections of cladding no. 5: a) overview, b-d) detailed microstructures near the interface, in the middle and near the surface, respectively

\section{CONCLUSIONS}

Pilot experiments aimed at formation of W-Cu composites on W substrates by PTA cladding were carried out. The formation of dense claddings with several $\mathrm{mm}$ thickness and good bonding of the tungsten and copper phases was successfully demonstrated. The influence of certain process parameters, affecting mainly the heat input to the filler and base materials was at least qualitatively indicated. Although the claddings were prepared with a stepwise varying $\mathrm{W} / \mathrm{Cu}$ ratios, they did not feature a steady compositional gradation. This can be attributed to the intense mixing of the layers in the melt pool, due to high heat input from the torch and dynamic effect of the plasma jet; the largely different densities and melting points of the two phases may have contributed to this as well. The intermixing can be reduced by lowering the heat input to the layers, e.g. by lowering the torch current or increasing the traverse velocity, which would result in a shallower melt pool. Still, 
even in the current form, the composites would be usable for reducing the stress concentration compared to a sharp tungsten/copper interface. During these experiments, irregular powder feeding resulted in structural and compositional inhomogeneities. This might have been a temporary issue only, as such problems were not experienced in other similar experiments $[24,27]$. They may be alleviated by using spherical powders, which feature better flowability. The abovementioned modifications can be the subject of further process optimization.

\section{ACKNOWLEDGEMENTS}

\section{This work was supported by the Czech Academy of Sciences through the Strategy AV21 program.}

\section{REFERENCES}

[1] CHAPMAN, I. Putting the sun in a bottle: The path to delivering sustainable fusion power. The Royal Society Kavli Medal and Lecture [online]. 2019. [viewed: 2021-03-24]. Available from: https://www.youtube.com/watch?v=eYbNSgUQhdY

[2] ROMANELLI, F. Fusion Electricity: A roadmap to the realisation of fusion energy. European Fusion Development Agreement, 2012.

[3] MATĚJÍČEK, J. Materials for fusion applications. Acta Polytech. 2013, vol. 2, pp. 197-212.

[4] PINTSUK, G. Tungsten as a plasma-facing material. In: Comprehensive Nuclear Materials, ed. Konings, R. J. M. Elsevier. 2012. pp. 551-581.

[5] PHILIPPS, V. Tungsten as Material for Plasma-Facing Components in Fusion Devices. J. Nucl. Mater. 2011, vol. 415, no. 1, pp. S2-S9.

[6] HEUER, S., COENEN, J. W., PINTSUK, G., MATĚJIČEEK, J., VILÉMOVÁ, M., LINSMEIER, CH. Overview of challenges and developments in joining tungsten and steel for future fusion reactors. Physica Scripta. 2020, vol. T171, paper no. 014028.

[7] WEBER, T., AKTAA, J. Numerical Assessment of Functionally Graded Tungsten/Steel Joints for Divertor Applications. Fusion Eng. Des. 2011, vol. 86, no. 2-3, pp. 220-226.

[8] ITOH, Y., TAKAHASHI, M. \& TAKANO, H. Design of tungsten/copper graded composite for high heat flux components. Fusion Eng. Des. 1996, vol. 31, pp. 279-289.

[9] NEU, R. et al. Investigations on Tungsten Heavy Alloys for Use as Plasma Facing Material. Fusion Eng. Des. 2017, vol. 124, pp. 450-454.

[10] NEU, R. et al. Results on the Use of Tungsten Heavy Alloys in the Divertor of ASDEX Upgrade. J. Nucl. Mater. 2018, vol. 511, pp. 567-573.

[11] ROOSTA, M., BAHARVANDI, H. The comparison of W/Cu and W/ZrC composites fabricated through hot-press. Int. J. Refract. Met. Hard Mater. 2010, vol. 28, pp. 587-592.

[12] TANG, X. et al. Fabrication of W-Cu functionally graded material by spark plasma sintering method. Int. J. Refract. Met. Hard Mater. 2014, vol. 42, pp. 193-199.

[13] MONDAL, A., AGRAWAL, D., UPADHYAYA, A. Microwave sintering of refractory metals/alloys: W, Mo, Re, W$\mathrm{Cu}, \mathrm{W}-\mathrm{Ni}-\mathrm{Cu}$ and W-Ni-Fe alloys. J. Microw. Power Electromagn. Energy. 2010, vol. 44, pp. 28-44.

[14] MÜLLER, A. V. et al. Application of tungsten-copper composite heat sink materials to plasma-facing component mock-ups. Physica Scripta. 2020, vol. T171, paper no. 014015.

[15] HE, G. et al. Preparation of tungsten fiber reinforced-tungsten/copper composite for plasma facing component. J. Nucl. Mater. 2014, vol. 455, pp. 225-228.

[16] PETROVSKIY, P., DOUBENSKAIA, M., SOVA, A., TRAVYANOV, A. Analysis of copper-tungsten cold spray coating: Kinetics of coating formation and its thermal properties. Surf. Coatings Technol. 2020, vol. 385, paper no. 125376.

[17] PINTSUK, G., BRÜNINGS, S. E., DÖRING, J. E., LINKE, J., SMID, I., XUE, L. Development of W/Cu Functionally Graded Materials. Fusion Eng. Des. 2003, vol. 66-8, pp. 237-240.

[18] DÖRING, J. E., VASSEN, R., PINTSUK, G., STÖVER, D. The processing of vacuum plasma-sprayed tungstencopper composite coatings for high heat flux components. Fusion Eng. Des. 2003, vol. 66-8, pp. 259-263. 
[19] WEBER, T. et al. Functionally Graded Vacuum Plasma Sprayed and Magnetron Sputtered Tungsten/Eurofer97 Interlayers for Joints in Helium-Cooled Divertor Components. J. Nucl. Mater. 2013, vol. 436, no. 1-3, pp. $29-39$.

[20] MATĚJíČEK, J., ZAHÁLKA, F., BENSCH, J., CHI, W., SEDLÁČEK, J. Copper-tungsten composites sprayed by HVOF. J. Therm. Spray Technol. 2008, vol. 17, pp. 177-180.

[21] MATĚJÍČEK, J., ANTOŠ, J., ROHAN, P. W + Cu and W + Ni composites and FGMs prepared by plasma transferred arc cladding. Materials. 2021, vol. 14, paper no. 789.

[22] MATĚJíČEK, J., CHRÁSKA, P., LINKE, J. Thermal Spray Coatings for Fusion Applications - Review. J. Therm. Spray Technol. 2007, vol. 16, no. 1, pp. 64-83.

[23] VERGARA, V., DUTRA, J.C., D'OlIVEIRA, A.S. Hardfacing by Plasma Transferred Arc Process. In: Arc Welding, ed. Sudnik, W. InTechOpen. 2011. pp. 3-20.

[24] RYBíN, J. Plasma overlays of tungsten for fusion applications. Prague, 2020. Master Thesis. Czech Technical University in Prague.

[25] VÝLETOVÁ, K. PTA deposition on metallic substrate. Prague, 2019. Bachelor Thesis. Czech Technical University in Prague.

[26] VOSÁHLO, J. PTA deposition of copper and tungsten for fusion reactors. Prague, 2020. Master Thesis. Czech Technical University in Prague.

[27] ANTOŠ, J. PTA Cladding of materials for the first wall of fusion reactors. Prague, 2018. Master Thesis. Czech Technical University in Prague. 